\title{
OPTIMIZATION OF PROCEDURE FOR DYEING WITH PURE NATURAL DYE
} OBTAINED FROM TURMERIC MAMTA VASHISHTHA $^{1} \&$ SHAHNAZ JAHAN ${ }^{2}$

${ }^{I}$ Associate Professor, Amity School of Fashion Technology, Amity University Rajasthan, Kant Kalwar, Jaipur, India

${ }^{2}$ Professor and Head, Department of Clothing and Textiles,

G.B. Pant University of Agriculture \& Technology, Pantnagar, India

\section{ABSTRACT}

Preservation and protection of the environment is one of the most talked about subject in today's industrial and social discourses. The latest trend is purely to make natural dye stuffs. The use of harmful metallic mordants in natural dyes can be replaced by natural mordants to make purely natural dye stuffs. India was the source of earliest natural dyestuffs known to man. The History of dyeing is divided by the date 1856, the year in which Sir William Henry Perkin discovered Mauve the first synthetic dye (Comptons Pictured Encyclopedia). Rapid research strides in synthetic chemistry, supported by the industrialization of textile production not only led to the development of synthetic alternatives to popular natural dyes, but also to a number of synthetic dyes in various hues and colours, that gradually pushed the natural dyes into oblivion. However, environmental issues in the production and application of synthetic dyes once again revived consumer's interest in natural dyes during the last decades of the twentieth century (GULRAJANI M L). The present study was aimed to develop 100\% natural bright yellow colour for dyeing of wool, without the use of any synthetic stuffs as mordants.

The water soluble yellow dye from turmeric rhizomes (Curcumin) is very fugitive in nature. The hue becomes dull with exposure to time and temperature. The conventional aqueous extraction procedure involves a time gap between the extraction of dye and actual dyeing of the substrate. This exposure to time gap makes the dye dull and unappealing. To achieve the best dyeing results, another way of dyeing was tried and tested, "Simultaneous extraction and dyeing" where, dyeing of substrate is carried out in the same water bath along with the extraction of dye from the raw material. A series of experiments were conducted to compare and analyze the results two different procedures of dyeing, by means of calorimetric analysis, and visually, by trained subject experts. Simultaneous extraction and dyeing method was found to yield best hues of yellow dye, as decided by calorimetric tests and visual analysis. The colours are brighter and appealing as the dye is absorbed by the substrate, as soon it is released in water bath. Different variables standardized were; Method of dyeing, concentration of dye material, temperature for extraction, temperature for dyeing, time for extraction and time for dyeing.

The final samples were tested for fastness to light and washing as per the standards laid by Bureau of Indian standards.

KEYWORDS: Turmeric Rhizomes, Curcumin, Aqueous Extraction of Dye, Colourimetric Tests \& "Simultaneous Extraction and Dyeing”

Received: Feb 11, 2017; Accepted: Feb 28, 2017; Published: May 20, 2017; Paper Id.: IJTFTJUN20171

\section{INTRODUCTION}

Synthetic dyes are produced at high temperature and pressure from chemicals isolated from petroleum 
derivatives. During the manufacturing process of dyes, many carcinogenic chemicals are used which leads to the formation of toxic bi-products. These bi-products are discharged into the rivers, ponds or left in open, hence causing severe atmospheric pollution (Paul R, 1996). This has threatened the ecological balance and called the attention of the environmentalists to develop eco-friendly technologies to produce dyes from natural sources (Neelam Pruthi, 2007). The present study is aimed at developing 100\% natural bright yellow colour for dyeing of wool, without the use of any synthetic stuff as mordants. A number of shades were developed with good to excellent washing fastness, through variations in dyeing conditions only. No synthetic chemical was used at any stage. Various studies have been carried out by different scientists on turmeric dye. However, optimizing the dyeing conditions for turmeric dye, using simultaneous dyeing and extraction technique for dyeing of wool, investigated in the present study have not been reported earlier.

\section{MATERIALS AND METHODS}

\section{Collection of Raw Materials and their Preparation}

Plant Materials: Common name: Turmeric, Botanical name: Curcuma Longa

Family: Ginger family, Zingiberaceae. It is native to Southern Asia, requiring temperatures between 20 and 30 ${ }^{\circ} \mathrm{C}\left(68\right.$ and $\left.86{ }^{\circ} \mathrm{F}\right)$, and a considerable amount of annual rainfall to thrive (Image- 3 )

Part used: Rhizomes, When not used fresh the rhizomes are boiled for about 30-45 minutes and then dried in hot ovens, after which, it is ready for sale in the market for further use as a coloring agent for food and dyes. Dried Turmeric Rhizomes were collected from the local market complex in G. B. Pant University campus, Pantnagar, Udham Singh Nagar, Uttarakhand. Rhizomes were dried in shade and pulverized in a powder form (Image: 2)

\section{Instruments}

- Wiley mill installed in the department of Post Harvest Technology, College of Technology, Pantnagar was used for pulverizing the Turmeric Rhizomes.

- The optical density of dye solutions was measured by Spectrophotometer- G5866C installed in the department of Chemistry, College of Basic sciences and Humanities, Pantnagar.

- Electronic balance was used for weighing the dye materials and wool.

- Water bath with thermostatic temperature control was used for dyeing the wool samples in glass beakers under controlled conditions (Image: 4).

- Mercury Bulb Tungston fluorescent lamp (MBTF) Light fastness Tester installed at the department of Textile Technology, IIT Delhi was used to test the colour fastness of dyed samples to light.

- Atlas Launder' ometer installed in the department of Textile Technology, IIT Delhi was used for testing, washing fastness of dyed samples (Image: 4)

Wool

White Australian Merino wool was purchased from the Shree Gandhi Ashram, Haldwani, Uttarakhand (Image 1).

\section{Blue Wool Standards}

Blue Wool standards were used (for fading along with samples) for testing colour fastness to light (Image: 7). 


\section{Gray Scale}

- The colour fastness rating was done with Gray Scale for evaluating changes in colour and staining as per ISO recommendations (ISO 105-A02: 1993 and ISO 105-A-03) (Image: 5).

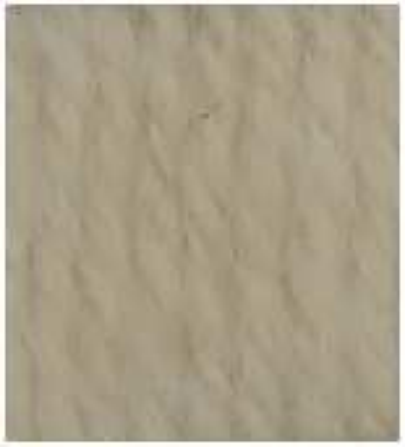

Image 1: The Un-Dyed Wool Sample



Image 2: Turmeric Rhizome and Powder

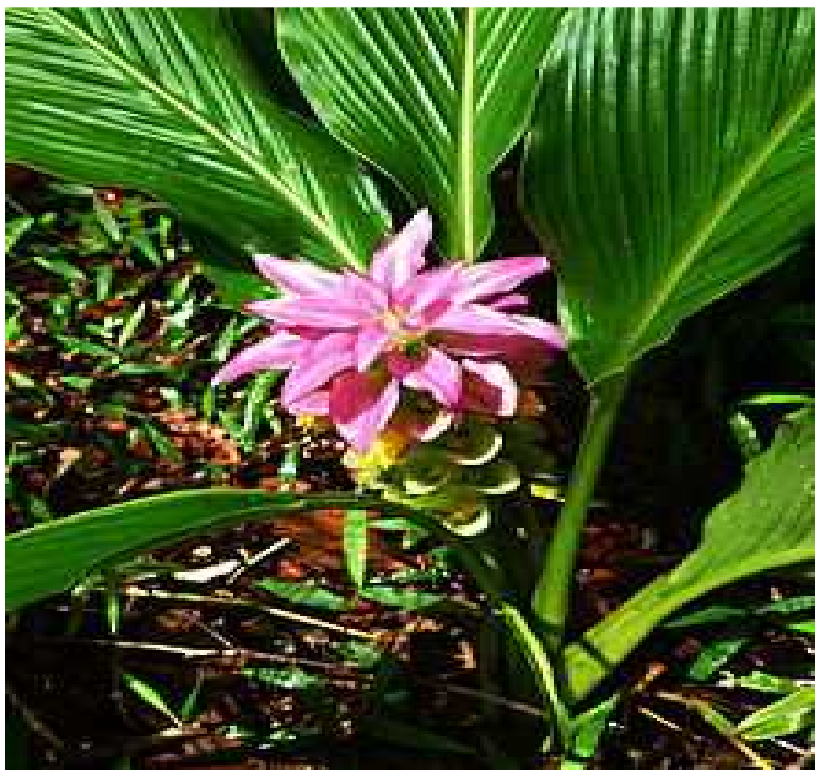

Image 3: Inflorescence of Curcuma_longa (Turmeric)
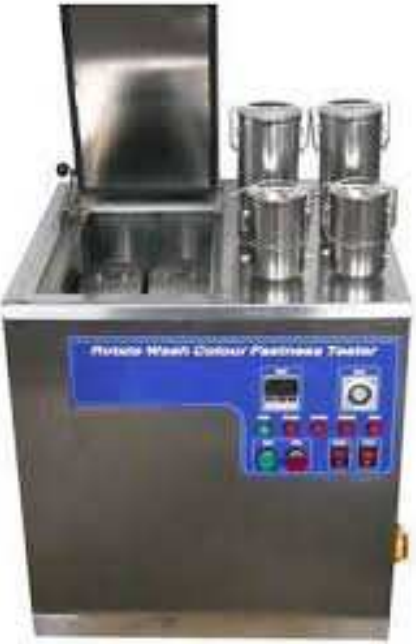

Image 4: Launderometer



Image 5: Gray Scale 




Image 6: The Water Bath for Dyeing Experiments

Processing of Wool: The scouring of wool was done according to the procedure mentioned by Hover 1976. A detergent solution of $1 \mathrm{ml}$ of Genteel with $100 \mathrm{ml}$ of hot water was prepared. When it was cooled to lukewarm, skeins of wool was immersed. Theses skeins were stirred with a wooden spoon for 30 minutes. Later skiens were taken out, rinsed with lots of warm water. This treatment was repeated for three to four times, every time the detergent quantity was reduced. The skins were squeezed and rinsed with tap water, till they were freed of the traces of detergent (care was taken not to scrub wring or mingle the skeins as it might cause hardening and matting of wool). Washed skeins of wool were allowed to dry and finally weighed for further experimentation.

\section{Optimization of Different Variables}

A series of experiments were conducted in order to standardize the different variables; such as dyeing technique, concentration of the dye material, time for extraction of dye, time for dyeing, temperature for extraction and temperature for dyeing.

For the dyeing of samples the MLR (material liquor ratio) selected was 1:10. The Optical density (OD) values of the dye solutions, before and after dyeing were recorded. A sample of one $\mathrm{ml}$ was taken from each beaker, and the optical density was recorded by diluting it 20 times. The percent absorption was calculated by the following formula:

\%Absorption $=$ OD before dyeing - OD after dyeing $/$ OD before dyeing $\mathrm{X} 100$

Dyed samples were judged by a panel of 15 judges visually on the criteria of luster, evenness of dye, depth of shade and overall appearance. From the total marks obtained, the percentage ratings were calculated. Each optimized variable was used in further experiments, wherever desired.

The final range of shades was tested for colour fastness to light and washing at the Department of Textile Technology, IIT Delhi.

\section{DYEING TECHNIQUES}

\section{Technique I}

Turmeric powder was tied in muslin bags ( 2 inch X 2 inch) with a thread to hold it. Pre soaked and weighed wool sample, and dye bag was put in a beaker containing $100 \mathrm{ml}$ water. The beaker was placed in a boiling water bath $\left(100^{\circ} \mathrm{c}\right)$. Simultaneous extraction and dyeing was carried out in glass beakers for one hour.

Samples were stirred and dye bags were pounded with a glass rod after every five minutes, to ensure even dyeing and continuous extraction of dye from muslin bag. After one hour, dye bags were taken out and dyed samples were allowed to cool in dye bath itself. Then, the samples were rinsed under running water and dried in shade. 


\section{Technique II}

In this technique, the conventional method of dyeing has been used. The dye was extracted for one hour in a boiling water bath $\left(100^{\circ} \mathrm{c}\right)$. The solution was then cooled and filtered. Pre soaked wool sample of $10 \mathrm{~g}$ was added to this dye solution, and dyeing was carried out at $80^{\circ} \mathrm{c}$ for one hour. The samples were stirred with a glass rod after every 10 minutes in order to obtain an even dyeing on the sample. After one hour, beakers were taken out of water bath and samples were allowed to cool in dye bath itself. Dyed samples were then rinsed under tap water and dried in shade.

According to results obtained, Technique I was selected for Turmeric dye. For further experiments, Technique I was used.

\section{Measuring the Optical Density While Using Technique I}

During further experiments while using technique I, each experiment was carried out as a pair of two. In each pair of two beakers, two dye bags with the same contents and water were placed, but presoaked weighed wool sample was added only to one beaker and both beakers were placed in the dye bath for extraction and dyeing. This was done in order to facilitate the recording of the optical density, before and after dyeing. Thus, for each experiment, the number of specimen dye solutions was doubled. For example, for optimization of concentration at 3 different concentrations, $1 \mathrm{~g}, 2 \mathrm{~g}$, \& $3 \mathrm{~g}$ were tested. Two bags for each quantity- total 6 dye bags were placed in separate beakers to carry out the experiment.

\section{Concentration of Dye Material}

For optimization of concentration of Turmeric dye, 3 different concentrations, i.e. $1 \mathrm{~g}, 2 \mathrm{~g}, \& 3 \mathrm{~g}$ were tested, Simultaneous extraction and dyeing was carried out for one hour at $100^{\circ} \mathrm{c}$. The remaining process was repeated as explained earlier. Optical density was measured for all six solutions and dyed samples were evaluated by judges.

\section{Time for Simultaneous Extraction \& Dyeing}

Simultaneous extraction and dyeing was carried out with optimized concentration, for three different time durations i.e. $60,120,180$ minutes respectively, at $100^{\circ} \mathrm{c}$. The rest of the procedure was done as mentioned earlier. Optical density was measured for all six solutions and dyed samples were evaluated by judges.

\section{Temperature for Simultaneous Extraction \& Dyeing}

Simultaneous extraction and Dyeing were carried out with the optimum concentration of dye for optimized time duration at four different temperatures i.e. $40^{\circ} \mathrm{c}, 60^{\circ} \mathrm{c}, 80^{\circ} \mathrm{c}, 100^{\circ} \mathrm{c}$. Optical density was measured for all eight solutions, and dyed samples were evaluated by judges.

\section{Preparation of Final Samples}

A final sample was prepared by dyeing the presoaked weighed wool sample with Turmeric, using all optimized variables i.e. optimized dyeing technique, optimized concentration of dye material, optimizing them for extraction and dyeing and optimized temperature for extraction and dyeing. This sample was prepared for final tests to colour fastness and washing (Table 5)

As per the results of an evaluation by judges, the shades out of 13 shades were selected. Finally, 9 different shades of yellow were included in the final range of shades (table 5). Further, tests of the final range of shades for colour fastness to light, and washing were done at the Department of Textile Technology, IIT Delhi. 


\section{Colour Fastness Tests of Dyed Samples}

\section{Colour fastness to Light}

The dyed wool yarns were mounted on a $6 \mathrm{~cm}$ wide cardboard frame in a sheet form (of parallel lengths) of $3 \times 6$ $\mathrm{cm}$ size. Along with these, Blue wool standards were also mounted. A strip of thick black chart paper was pinned up, so as to cover a half portion of the specimen and standards. Thus, samples half exposed were put inside Fadometer, and faded as per ISO recommendations. The standards and specimen were checked after every few hours, till a contrast between exposed and unexposed parts of the specimen was equivalent to grade 3 , on the gray scale. The samples were compared with Blue wool standards and rated (Image 7).

\section{Colour Fastness to Washing}

Yarns of the test samples were made in sheet form of parallel length measuring $10 \times 4 \mathrm{~cm}$, and placed between two pieces of undyed fabrics of the same size. The fabric on one side was wool and on the other side was cotton. These three layers were sewn from all sides to form a composite specimen (Image: 8). Soap solution prepared for testing and washing fastness had $5 \mathrm{ml}$ of Genteel per liter. Each composite sample was treated in the Launder'o meter for 45 minutes, at a temperature of $50 \pm 2^{\circ} \mathrm{c}$. The liquor: material ratio was 50:1. The samples were removed from Launder' ometer, rinsed thoroughly under running tap water, dried and ironed.

The samples were graded on the basis of change in colour of the samples, and also the staining of the adjacent fabrics with the help of Gary scales.

\section{Evaluation of the Samples for Fastness to Light and Washing}

The rating of the samples for fastness to light and washing was done as follows;

$\begin{array}{llll}\text { Rating for Colour Fastness to Light- } & 6 & \text { very good } \\ & 5 & \text { Fairly Good } \\ & 4 & \text { fair } \\ & 3 & \text { Poor } \\ \text { Rating for Change in Colour } & 2 & \text { Very Poor } \\ & 1 & \text { Excellent } \\ & 5 & \text { Good } \\ & 4 & \text { Fair } \\ \text { Rating for Staining } & 3 & \text { Poor } \\ & 2 & \text { Very Poor } \\ & 1 & \text { Negligible or no staining } \\ & 5 & \text { Slightly stained }\end{array}$




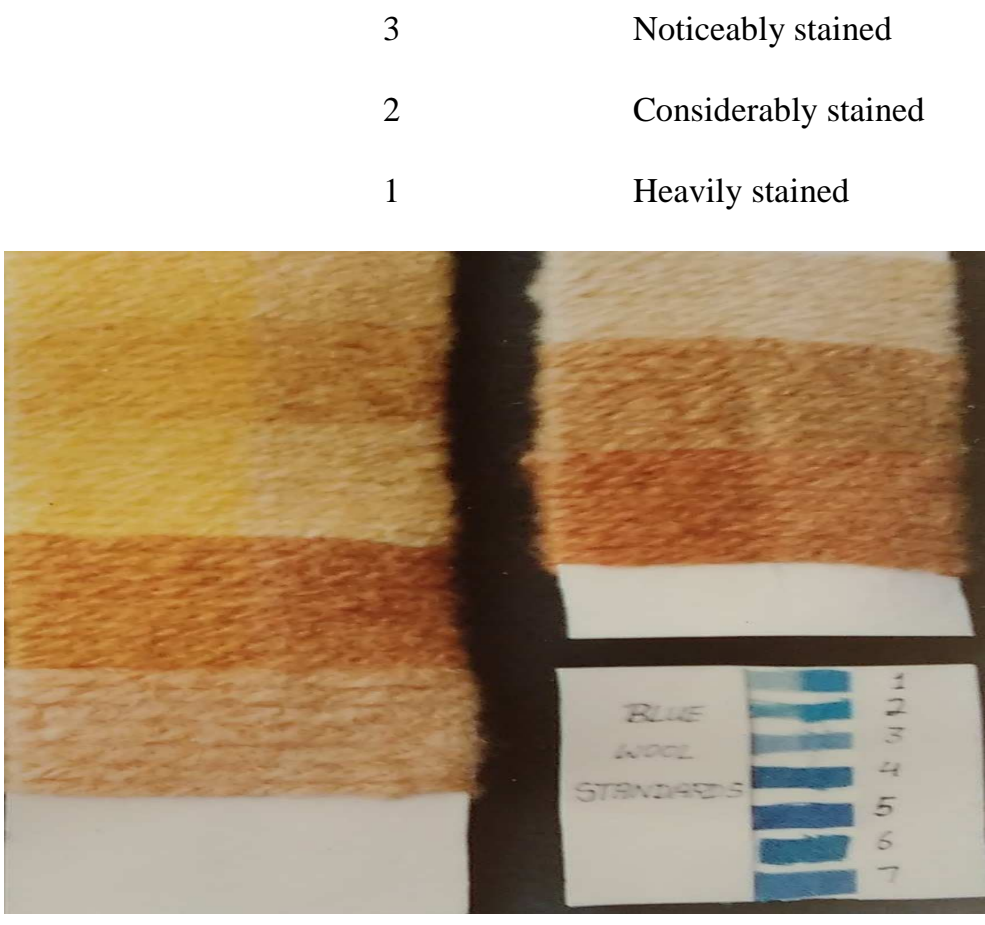

Image 7: Specimen Showing Contrast after Light Fastness Test

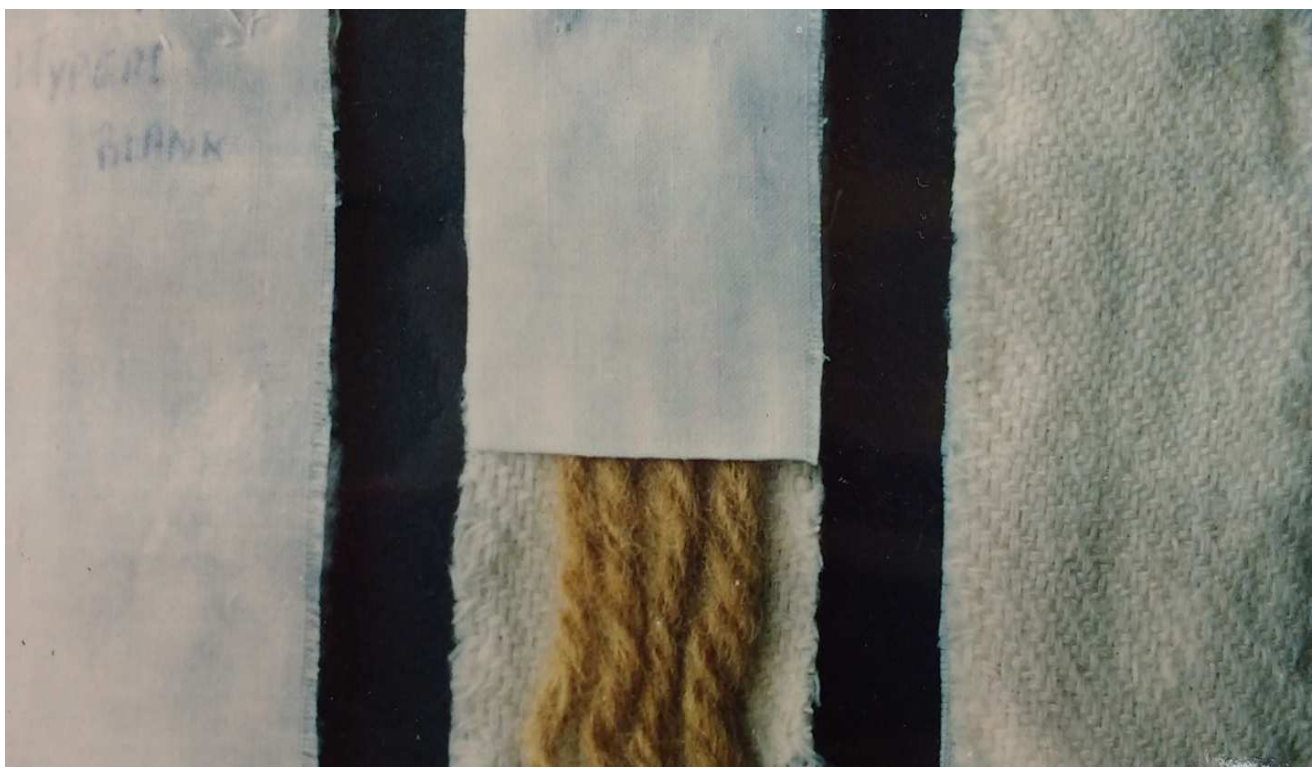

Image 8: Specimen for Washing Fastness Test (All 3 Layers Visible, Specimen Placed between Cotton \& Wool Fabric)

\section{RESULTS AND DISCUSSIONS}

Turmeric is one of the oldest natural colouring agents used throughout the world from ancient times (Gulrajani M L). The rhizomes of the perennial turmeric are the sources of colour. It is cultivated in almost all the parts of India. Curcumin is the prime principal constituent of yellow dye, along with other constituents like monodesmethoxycurcumin and bidesmethoxycurcumin, which also contributes fewer amounts of pigment and flavor (GULRAJANI M L).

Under experimental trials, different methodologies were adopted for the extraction of colour and dyeing of wool. Figures and tables 1 to 4 show the results of the experiments. 




Figure 1

Table 1

\begin{tabular}{|l|c|c|c|c|}
\hline Dyeing Technique & $\begin{array}{c}\text { O.D. Before } \\
\text { Dyeing }\end{array}$ & $\begin{array}{c}\text { O.D. After } \\
\text { Dyeing }\end{array}$ & $\begin{array}{c}\text { Percent } \\
\text { Absorption }\end{array}$ & $\begin{array}{c}\text { Percentage of } \\
\text { Visual Rating }\end{array}$ \\
\hline Dyeing Technique I & 0.27 & 0.2 & 25.92 & 64.33 \\
\hline Dyeing Technique II & 0.2 & 0.15 & 25 & 44.83 \\
\hline
\end{tabular}

Figure $1 \&$ Table 1: Percentage ratings of visual analysis and dye absorption percentage with different methods of dyeing for Turmeric (wave length- $380 \mathrm{~nm}$ )



Figure 2

Table 2

\begin{tabular}{|c|c|c|c|c|}
\hline $\begin{array}{c}\text { Conc. of Dye } \\
(\mathbf{g} / \mathbf{1 0 0 m l})\end{array}$ & $\begin{array}{c}\text { O.D. Before } \\
\text { Dyeing }\end{array}$ & $\begin{array}{c}\text { O.D. After } \\
\text { Dyeing }\end{array}$ & $\begin{array}{c}\text { Percent } \\
\text { Absorption }\end{array}$ & $\begin{array}{c}\text { Percentage of } \\
\text { Visual Rating }\end{array}$ \\
\hline 1 & 0.24 & 0.18 & 25 & 44.33 \\
\hline 2 & 0.26 & 0.19 & 26 & 67.33 \\
\hline 3 & 0.25 & 0.18 & 28 & 54.5 \\
\hline
\end{tabular}

Figure $2 \&$ Table 2: Percentage ratings of visual analysis and dye absorption percentage (at $380 \mathrm{~nm}$ ) with different concentrations of dye for Turmeric 


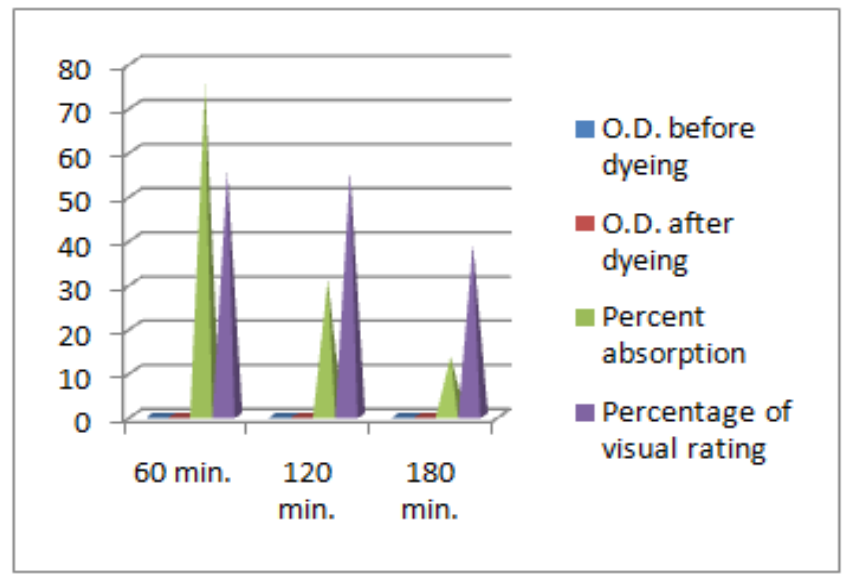

Figure 3

Table 3

\begin{tabular}{|c|c|c|c|c|}
\hline $\begin{array}{c}\text { Time for Simultaneous } \\
\text { Extraction and Dyeing } \\
\text { (min.) }\end{array}$ & $\begin{array}{c}\text { O.D. Before } \\
\text { Dyeing }\end{array}$ & $\begin{array}{c}\text { O.D. After } \\
\text { Dyeing }\end{array}$ & $\begin{array}{c}\text { Percent } \\
\text { Absorption }\end{array}$ & $\begin{array}{c}\text { Percentage of } \\
\text { Visual Rating }\end{array}$ \\
\hline $60 \mathrm{~min}$. & 0.16 & 0.04 & 75 & 55.5 \\
\hline $120 \mathrm{~min}$. & 0.13 & 0.09 & 30.76 & 55.3 \\
\hline $180 \mathrm{~min}$. & 0.15 & 0.13 & 13.33 & 38.83 \\
\hline
\end{tabular}

Figure 3 \& Table 3: Percentage ratings of visual analysis and dye absorption percentage (at $380 \mathrm{~nm}$ ) at different time durations for Turmeric dye

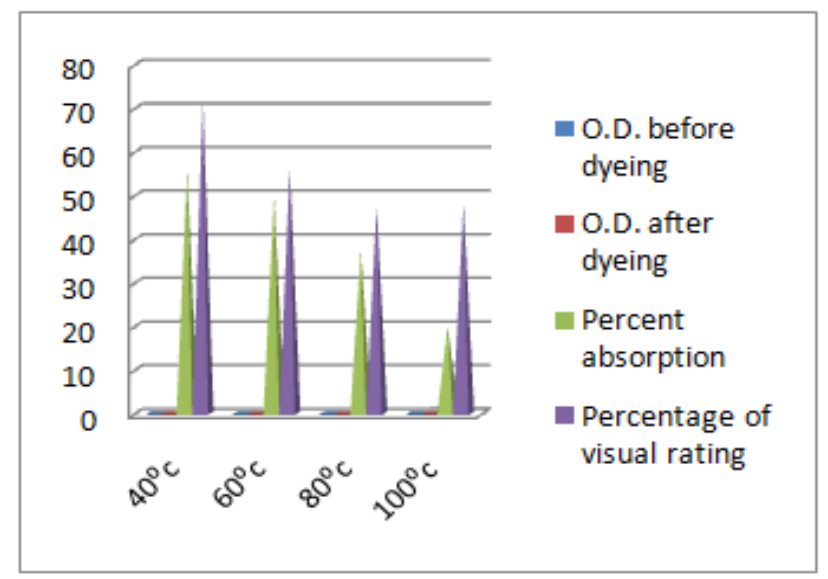

Figure 4

Table 4

\begin{tabular}{|c|c|c|c|c|}
\hline $\begin{array}{c}\text { Temperature for } \\
\text { Simultaneous } \\
\text { Extraction and Dyeing }\end{array}$ & $\begin{array}{c}\text { O.D. Before } \\
\text { Dyeing }\end{array}$ & $\begin{array}{c}\text { O.D. After } \\
\text { Dyeing }\end{array}$ & $\begin{array}{c}\text { Percent } \\
\text { Absorption }\end{array}$ & $\begin{array}{c}\text { Percentage of } \\
\text { Visual Rating }\end{array}$ \\
\hline $40^{\circ} \mathrm{c}$ & 0.25 & 0.11 & 56 & 72 \\
\hline $60^{\circ} \mathrm{c}$ & 0.2 & 0.1 & 50 & 56.33 \\
\hline $80^{\circ} \mathrm{c}$ & 0.16 & 0.1 & 37.5 & 47.66 \\
\hline $100^{\circ} \mathrm{c}$ & 0.15 & 0.12 & 20 & 48.16 \\
\hline
\end{tabular}


Figure 4 \& Table 4: Percentage ratings of visual analysis and dye absorption percentage (at $380 \mathrm{~nm}$ ) at different temperatures for Turmeric dye

Table 5: The Different Shades of Yellow Produced by Variations in Dyeing Parameters

\begin{tabular}{|c|c|c|c|}
\hline SN & Sample Code & Sample & Description of Dyeing Procedure \\
\hline 1. & Pale Dijon & & $\begin{array}{l}\text { Dyeing technique I - simultaneous extraction and dyeing, } \\
\text { Concentration of dye- } 1 \% \text {, temperature- } 100^{\circ} \mathrm{c} \text {, dyeing } \\
\text { duration- } 1 \text { hour. }\end{array}$ \\
\hline 2. & Flaxen & & $\begin{array}{l}\text { Dyeing technique II - Dyeing post extraction } \\
\text { Concentration of dye- } 1 \% \text {, Extraction temperature- } 100^{\circ} \mathrm{c} \text {, } \\
\text { extraction duration- } 1 \text { hour, Dyeing temperature- } 80^{\circ} \mathrm{c} \text {, } \\
\text { Dyeing time } 1 \text { hour. }\end{array}$ \\
\hline 3. & Dijon & & $\begin{array}{l}\text { Dyeing technique I - simultaneous extraction and dyeing, } \\
\text { Concentration of dye- } 2 \% \text {, temperature- } 100^{\circ} \mathrm{c} \text {, dyeing } \\
\text { duration- } 1 \text { hour. }\end{array}$ \\
\hline 4. & $\begin{array}{l}\text { Dandelion } \\
\text { Yellow }\end{array}$ & & $\begin{array}{l}\text { Dyeing technique I - simultaneous extraction and dyeing, } \\
\text { Concentration of dye- } 3 \% \text {, temperature- } 100^{\circ} \mathrm{c} \text {, dyeing } \\
\text { duration- } 1 \text { hour. }\end{array}$ \\
\hline 5. & Straw Yellow & & $\begin{array}{l}\text { Dyeing technique I - simultaneous extraction and dyeing, } \\
\text { Concentration of dye- } 2 \% \text {, temperature- } 100^{\circ} \mathrm{c} \text {, dyeing } \\
\text { duration- } 2 \text { hours. }\end{array}$ \\
\hline 6. & Lion Yellow & & $\begin{array}{l}\text { Dyeing technique I - simultaneous extraction and dyeing, } \\
\text { Concentration of dye- } 2 \% \text {, temperature- } 100^{\circ} \mathrm{c} \text {, dyeing } \\
\text { duration- } 3 \text { hours. }\end{array}$ \\
\hline 7. & Corn Silk & & $\begin{array}{l}\text { Dyeing technique I - simultaneous extraction and dyeing, } \\
\text { Concentration of dye- } 2 \% \text {, temperature- } 40^{\circ} \mathrm{c} \text {, dyeing } \\
\text { duration- } 1 \text { hour. }\end{array}$ \\
\hline 8. & Ripe Hay & & $\begin{array}{l}\text { Dyeing technique I - simultaneous extraction and dyeing, } \\
\text { Concentration of dye- } 2 \% \text {, temperature- } 60^{\circ} \mathrm{c} \text {, dyeing } \\
\text { duration- } 1 \text { hour. }\end{array}$ \\
\hline 9. & Pale Flaxen & & $\begin{array}{l}\text { Dyeing technique I - simultaneous extraction and dyeing, } \\
\text { Concentration of dye- } 2 \% \text {, temperature- } 80^{\circ} \mathrm{c} \text {, dyeing } \\
\text { duration- } 1 \text { hour. }\end{array}$ \\
\hline
\end{tabular}


Figure $1 \&$ table 1 show the results of calorimetric analysis (at $380 \mathrm{NM}$ ) and visual analysis of various parameters, explained earlier. As per the results, technique one was selected as appropriate for turmeric dye, as this produced much bright hue as compared to dyeing technique II.

Figure $2 \&$ Table 2 reveal the results of optimization of concentration of Turmeric dye. According to results, $2 \mathrm{gms}$ of Turmeric per $100 \mathrm{ml}$ of water, for dyeing $10 \mathrm{GM}$ of wool was found as optimum concentration. Anshu (1987) has recommended that, $2 \mathrm{GM}$ of dye is required per gm of wool, to obtain optimum colour from natural dye Turmeric. This is bit different from findings of the present study i.e. $2 \mathrm{gm}$ of Turmeric dye is required to dye 10 gm of wool. This variation in findings may be, due to natural variation in sources of dyes used and also wool used. It's a well known fact that, properties of natural products vary too much because of variation in the environment, and nourishment of the source used.

Results of calorimetric analysis and visual analysis (to optimize the time for dyeing) show that, 60 min. Dyeing time is appropriate for Turmeric. Maximum dye absorption was found at $60 \mathrm{~min}$. Duration (Table 3 and Figure 3 ). Results show that dyeing beyond 60 min. makes the hue dull. The decrease in colour, strength for 120 minutes of dyeing may be attributed to disruption of dye molecules as a consequence of over dyeing (Nagia F A \& El- Mohamedi, 2007). Cavendish (1978) has reported that, the extraction time of natural dyes varies from 20 to 120 minutes. The observations of the present study fall within this range.

Figure 4 and table 4 show that $40^{\circ} \mathrm{c}$ temperature provides the best results for dyeing with Turmeric. Temperature beyond that, made the hue more Grayish. The Dye absorption was also found maximum at $40^{\circ} \mathrm{c}$. The results indicate that high temperature should be avoided for dyeing with turmeric, if a bright hue is required. However, Saima Umbreen et.al report that maximum colour strength is obtained at 90 (c but dyeing is not uniform. (Umbreen Saima, 2008)

Table 5 shows the various shades achieved through different dyeing procedures during the optimization process. The sample \#7 Corn Silk has been dyed with all optimized parameters (Dyeing technique myself, conch. Of dye $2 \%$, temperature $40^{\circ} \mathrm{c}$, Dyeing time- $60 \mathrm{~min}$.)

Table 6: Ratings for Colour Fastness to Light and Washing

\begin{tabular}{|c|l|c|c|c|c|}
\hline \multirow{2}{*}{ SN } & \multicolumn{1}{|c|}{\begin{tabular}{c} 
Colour Fastness to Washing \\
\cline { 4 - 6 }
\end{tabular}} & $\begin{array}{c}\text { Ratings for Colour } \\
\text { Fastness to Light }\end{array}$ & $\begin{array}{c}\text { Catings for } \\
\text { Colour Change }\end{array}$ & $\begin{array}{c}\text { Ratings for } \\
\text { Staining on } \\
\text { Cotton }\end{array}$ & $\begin{array}{c}\text { Ratings for } \\
\text { Staining on } \\
\text { Wool }\end{array}$ \\
\hline & Pale Dijon & $2-3$ & 4 & $3-4$ & 4 \\
\hline & Flaxen & 3 & 5 & 4 & $4-5$ \\
\hline & Dijon & 2 & 4 & 3 & 4 \\
\hline & Dandelion Yellow & 3 & $4-5$ & $3-4$ & 4 \\
\hline & Straw Yellow & 3 & $3-4$ & 5 & $3-4$ \\
\hline & Lion Yellow & 2 & 3 & 2 & 4 \\
\hline & Corn Silk & 2 & 4 & $3-4$ & 4 \\
\hline & Ripe Hay & 3 & 5 & 4 & $4-5$ \\
\hline
\end{tabular}

Table 6 shows the results of colour fastness tests to Light and Washing. Most of the shades exhibited poor to fair fastness to light. The samples were found to be affected by light rapidly. The shades processed at high temperature exhibited a bit better colour fastness to light. For shades done at high temperature, a grade of 3 (fair) was observed. Overall, the range of light fastness grades was between 2 to 3 (poor to fair).

Samples showed better grades for colour fastness to washing (3- 5). Best grades were observed in Flaxen, Ripe 
Hay and Pale flaxen (4- 5) as good to excellent for a change in colour, good for staining on cotton (4) and good to excellent for staining on wool. Lowest ratings were observed for Lion, Yellow. The rest of the shades got a satisfactory rating of good to excellent (4-5), for colour change and staining as well.

\section{CONCLUSIONS}

Today, the protection of environment has become a challenge for the chemical industries worldwide; All over the world, the environmental restrictions are becoming stricter. They need to realize the importance and the technology of natural dye as more urgent. This would then lead to the returning of traditional and more natural way of life (patel $\mathrm{BH}$ ). Results of numerous experiments reveal that, same dye produced different shades under different dyeing conditions. Standard recipes have been developed for each shade. A range of Flaxen to Dijon, Hay, straw, Dandelion, corn silk and Lion yellow were achieved (Table 5). Observations proved that, less temperature and reduced time of dyeing give better results, in terms of colour appeal. Whereas, analysis of the shade cards after a prolonged time gap shows that the high temperature and prolonged dyeing time produced shades with more durable dyeing. Thus, any of the dyeing technique can be used as per the requirement of end product. These colours were used at Alps industries ltd. Ghaziabad, UP for dyeing cotton for their export orders. To improve the light fastness of these dyes, dyeing was carried out at fiber stage, which improved the colour fastness to light up to grade 4 (a considerable improvement for colour fastness to light).

Experiments reveal that, this dye can be used as a safe eco friendly dye. Numerous shades ; Pale Dijon, Flaxen, Dijon, Dandelion yellow, Straw Yellow, Lion Yellow, Corn Silk, Ripe Hay, pale Flaxen have exhibited good washing fastness and fair light fastness. There is a lot of scope to use the Turmeric dye for obtaining numerous colour shades, using safe eco-friendly textile dyeing.

\section{ACKNOWLEDGEMENTS}

Authors are thankful to following agencies for their support extended during course of study;

Department of Clothing and Textiles, G B Pant University of Agriculture and Technology, Pantnagar, Uttarakhand

Department of Chemistry, G B Pant University of Agriculture and Technology, Pantnagar, Uttarakhand

Department of Post Harvest Tech., G B Pant University of Agriculture and Technology, Pantnagar, Uttarakhand

Department of Textile Technology, I.I.T., New Delhi

Alps Industries Ltd, Mohan Nagar, Ghaziabad, UP

\section{REFERENCES}

1. GULRAJANI M L, G. D. (1993). NATURAL DYES AND THEIR APPLICATION TO TEXTILES. NEW DELHI: I I T DELHI.

2. Gulrajani M L, G. D. (Jan 1992). Some studies on yellow natural dyes; Part I. Indian Textile Journal, $50-56$.

3. Neelam Pruthi, G. D. (2007). Dyeing of Silk with Barberry bark. Natural product Radiance, 40- 44.

4. Patel BH, A. B. (2006). improving the environmental and economic aspects of cotton dyeing using vegetable dyes. colourage, $6: 49-58$.

5. Paul R, J. M. (1996). Classification Extraction and fastness properties. textile Dyer and printer 31 (6, )16- 24. 
6. Umrao Singh and Others (1983). Dictionary of Economic plants in India. Indian council of Agricultural research, New delhi, $51-52$

7. Sachan $K \&$ Kapoor VP (April 2007) Optimization of extraction and dyeing conditions for traditional turmeric dye. Indian Journal of Traditional Knowledge, Vol6(2), 270 -278

8. ISI Hand Book of Textile Testing, (1982) Indian Standards institution, New Delhi, 538- 539, 571- 572

9. Umbreen S, Ali S, Hussain T \& Nawaz $R$ (2008).Dyeing properties of natural dyes extracted from Turmeric and their comparison with reactive dyeing. Research Journal of Textile and Apparel Vol 12 no 4

10. ABRAHART E N, DYES AND THEIR INTERMEDIATES, LONDON, OXFORD KERGAMON, 1977.

11. COMPTONS PICTURED ENCYCLOPEDIA, CHICAGO, F E, COMPTON ANDCOMPANY, 1955.

12. Nagia F A \& El-Mohamedi, R. 2. (2007). R.S.R. 2006. Dyes and Pigments vol 75 no 3, 550- 555. 
